\title{
A participação dos países em desenvolvimento e menos desenvolvidos no Órgão de Solução de Controvérsias da Organização Mundial do Comércio
}

\author{
The participation of developing countries and \\ least developed countries in the Dispute Settlement \\ Body of the World Trade Organization
}

DOI: $10.21530 /$ ci.v13n2.2018.760

Andréa Freire de Lucena ${ }^{1}$

Samuel Rufino de Carvalho ${ }^{2}$

\section{Resumo}

O Órgão de Solução de Controvérsias da Organização Mundial do Comércio almeja solucionar as disputas comerciais dos países, por meio da supervisão, do monitoramento e da averiguação do cumprimento de suas regras. Um dos entraves do sistema diz respeito às dessemelhanças entre países desenvolvidos e em desenvolvimento. Este artigo investiga a existência de assimetrias de participação entre os países menos desenvolvidos (PMD), países em desenvolvimento (PED) e países desenvolvidos (PD) no âmbito do Órgão de Solução de Controvérsias, desde a sua criação em 1995 até o ano de 2016. Os dados coletados foram trabalhados pelo uso dos métodos estatístico e comparativo, com a intenção de se obter uma análise minuciosa acerca das disputas comerciais e verificar os níveis de desigualdade de atuação na instituição. Observou-se que o Órgão possui assimetrias evidentes de participação, que refletem a divisão internacional do trabalho presente no sistema internacional, em que os Estados de maiores rendas atuam mais facilmente com vistas a suprir suas demandas.

Palavras-chave: Órgão de Solução de Controvérsias; Organização Mundial do Comércio; Assimetrias.

\footnotetext{
1 Professora e pesquisadora da graduação em Ciências Econômicas e do mestrado em Ciência Política da Universidade Federal de Goiás (UFG).

2 Discente do Programa de Mestrado em Ciência Política (UFG), com bolsa da Coordenação de Aperfeiçoamento de Pessoal de Nível Superior (CAPES). Graduou-se em 2016 em Relações Internacionais (UFG).

Artigo submetido em 27/01/2018 e aprovado em 30/08/2018.
} 


\begin{abstract}
The World Trade Organization's Dispute Settlement Body (DSB) seeks to resolve the trade disputes of countries through supervision, monitoring and enforcement of its rules. One of the barriers of the system concerns dissimilarities between developed and developing countries. This paper investigates the existence of asymmetries of participation amongst the least developed countries (LDC), the developing countries (DCs) and the developed countries (DC) within the Dispute Settlement Body, from its creation to 2016. The data collected were worked through the use of statistical and comparative methods, with the goal of obtaining a detailed analysis of the commercial disputes and verifying the levels of inequality within the institution. It was observed that the DSB has clear asymmetries of participation, which reflect the international division of labor present in the international system, where the higher income states act more easily in order to meet their demands.
\end{abstract}

Keywords: Dispute Settlement Body; World Trade Organization; Asymmetries.

\title{
Introdução
}

A Organização Mundial do Comércio (OMC), surgida em janeiro de 1995, é a principal instituição comercial de cunho global. Originada por meio da substituição do Acordo Geral de Tarifas e Comércio (Gatt), a organização tem como pedra angular conter os gargalos que enfraquecem o comércio internacional e promover mais segurança e estabilidade às relações multilaterais, utilizando-se cada vez mais de aparatos jurídicos como principal meio regulador.

A OMC apresenta-se como provedora de relações mais justas ao comércio mundial. Para isso, alguns princípios tornam-se fundamentais para a sua existência: o princípio da não discriminação, o qual assume a necessidade de tratar os outros atores igualmente; o princípio do livre-comércio, que deve ser estabelecido de forma gradual por meio das negociações; o princípio da previsibilidade, que presume a segurança e a transparência dos compromissos acordados; o princípio da promoção de competições justas; e o princípio de encorajamento do desenvolvimento e de reformas econômicas, que procura promover o crescimento das nações menos privilegiadas economicamente mediante um tratamento diferenciado (WTO, 2017c).

Para que os princípios da organização sejam assegurados, surgem algumas ferramentas auxiliadoras. Nesse sentido, o Órgão de Solução de Controvérsias (OSC) da OMC emerge como sendo um dos principais instrumentos do sistema multilateral de comércio. Baseando-se no Entendimento Relativo às Normas e 
Procedimentos sobre Solução de Controvérsias (ESC), o órgão atua como elemento fomentador dos princípios da organização, por intermédio das resoluções dos conflitos comerciais entre as nações.

Os países em desenvolvimento compõem mais de três quartos dos membros da OMC, e tiveram participações ativas no regime internacional de comércio durante as rodadas do Gatt (WTO, 2017b). Sob esse viés, a atuação desses países - consoante o último princípio descrito - torna-se o foco deste artigo, uma vez que se intenciona averiguar a assimetria de participação dos países em função do seu grau de desenvolvimento, por intermédio de uma análise do comportamento das nações perante o OSC. A questão norteadora desta investigação perquire se realmente há assimetrias de participação entre os países menos desenvolvidos, em desenvolvimento e desenvolvidos no âmbito do OSC. Caso haja, pretende-se averiguar se as teorias dos regimes conseguem explicar tais assimetrias.

A pesquisa recorreu a dois métodos de análise dos dados: o comparativo e o estatístico. O primeiro diz respeito à coleta de informações relacionadas às controvérsias internacionais levadas ao OSC. Para tanto, criou-se um banco de dados digital, que contribuiu para uma análise detalhada de todos os contenciosos existentes no Órgão até o ano de 2016. Tendo em vista a complexidade que envolve cada contenda comercial, a plataforma providenciou, de um modo dinâmico, um lócus único, onde todas as características relevantes das disputas estão presentes, o que permitiu a comparação entre os países. O trabalho apoiou-se na taxa de solução de controvérsias, que auxiliou a execução do segundo método, o estatístico.

O artigo está estruturado ao redor de dois pontos centrais. A primeira parte discorre sobre as teorias de regimes internacionais e a sua importância como aparato explicativo da atuação cooperativa dos atores. Na segunda parte, realiza-se uma análise detalhada dos 514 contenciosos levados ao OSC até dezembro de 2016. A investigação gira em torno das distintas participações entre os Países Menos Desenvolvidos (PMD), Países em Desenvolvimento (PED) e Países Desenvolvidos (PD). Por fim, discute-se alguns aspectos das teorias dos regimes que podem explicar os dados analisados e, consequentemente, as assimetrias.

\section{Regimes internacionais}

John Gerard Ruggie (1975) definiu regime como "um conjunto de expectativas mútuas, regras e regulamentos, planos, energias organizacionais e comprometimentos 
financeiros, os quais foram aceitos por um grupo de Estados"3 $(1975$, p. 570, tradução dos autores). A noção de regime embasa-se na ideia da existência de agentes reguladores das ações dos Estados, os quais contribuiriam à tendência de cooperação entre eles. Nesse sentido, Krasner (2012, p. 93) caracterizou regime como "princípios, normas, regras e procedimentos de tomada de decisões de determinada área das relações internacionais em torno dos quais convergem as expectativas dos atores".

A proposta de Krasner para a compreensão de regime tornou-se substancial na literatura existente sobre o tema. Para o autor, o termo deve ser entendido no sentido de "variáveis intervenientes, estando entre fatores causais básicos e os resultados e comportamentos relacionados" (KRASNER, 2012, p. 93). Ou seja, averígua-se nos regimes o pressuposto da existência de padrões de comportamentos compreendidos como recurso para se chegar a determinados resultados por meio da convergência de ações entre os atores. Desse modo, Krasner discorre sob uma perspectiva otimista a respeito da existência de regimes, ao analisar, sobretudo, como esses podem contribuir para os resultados do campo de interação dos agentes.

Pode-se compreender que o conceito de regimes está relacionado à noção de arranjos influenciadores do comportamento dos atores, que, muitas vezes, são entendidos como Estados nacionais. Para uma melhor compreensão de como os atores agem levando em consideração a existência dos regimes, faz-se necessário estudar o arcabouço teórico sobre o tema, que abarca três abordagens distintas, destacadas pelos enfoques no "poder, interesse ou conhecimento" (LUCENA, 2012, p. 34). Por seu turno, Krasner (2012) as define como estrutural convencional, estrutural modificada e grociana.

A primeira abordagem ressalta a indisposição dos Estados em cooperar. A interação entre as nações funciona como um espelho das relações de poder do sistema internacional. Encontram-se nas bases dessa premissa as concepções (neo)realistas das relações internacionais: fatores como natureza humana, ganhos relativos, Estados como os principais atores, anarquia, racionalismo, insegurança e sobrevivência tornam-se os quesitos primordiais que moldam as ações dos Estados. Krasner (2012, p. 97) define o campo teórico como estruturalista convencional, o qual "vê o conceito de regime como inútil, se não enganoso". Autores como Kenneth Waltz, Joseph Grieco e Susan Strange, entre outros, contribuíram com estudos tendo em vista as relações de poder como principais influentes da cooperação.

3 [A] set of mutual expectations, rules and regulations, plans, organizational energies and financial commitments, which have been accepted by a group of states. 
Nesse sentido, alguns estudiosos defendem a existência da teoria da estabilidade hegemônica e da relevância dos ganhos relativos como pressupostos que explicam a cooperação entre os Estados. A primeira assertiva diz respeito à propensão que os Estados têm a cooperar quando se estabelece um hegemon no sistema internacional. A potência hegemônica é caracterizada como a nação com maior poder relativo que possui, em alusão a Morgenthau (2003), os chamados elementos de poder nacional, como geografia, recursos naturais, capacidade industrial, preparação militar e população. De igual modo, aspectos como índole nacional, governo e diplomacia contribuem para o aumento do poderio de uma nação. Contudo, para o surgimento de uma potência hegemônica é necessário haver mais do que os elementos de poder, pois o país precisa ter a intenção de se propagar como hegemônico, sendo que, segundo Gramsci, a hegemonia pressupõe o consentimento do poder da nação mais forte pelos demais Estados (ALVES, 2010).

A segunda abordagem no campo das teorias de regimes é fundamentada pela interação dos atores baseada no interesse. O arcabouço teórico sugere que a intenção dos Estados em cooperar está ligada diretamente ao interesse que tais atores têm no sistema internacional. A vertente compartilha de algumas premissas da anterior, como os pressupostos de que os atores são racionais e buscam a maximização dos ganhos, o sistema internacional é anárquico e as instituições existem. Porém, as duas distinguem-se quanto ao grau de influência que os três fatores estabelecem em um Estado. Também denominada estruturalismo modificado, o quadro explicativo baseia-se nas teorias (neo)liberais das relações internacionais. Portanto, nota-se que as instituições internacionais se transformam em fatores atenuantes da anarquia, as quais possuem grande capacidade de influenciar o comportamento de uma nação. Arthur Stein, Robert Keohane e Joseph Nye contribuem para o campo teórico.

Um dos principais pressupostos de análise disserta que os atores buscam ganhos absolutos, pois, uma vez sendo racionais, as preocupações e ações permeiam somente seus ganhos e perdas individuais. Os Estados coordenam suas ações para que seja possível obter ganhos que não seriam adquiridos sem a cooperação. Posto isso, afigura-se a real função dos regimes internacionais: influenciar as preferências e facilitar a cooperação (KEOHANE, 1984). Compreende-se, desse modo, que os regimes internacionais são arranjos interestatais regulamentadores de determinadas áreas. Eles surgem com o objetivo de superar problemas de ação coletiva e coordenar o comportamento dos Estados, visando a um resultado minimamente benéfico a todos. 
As duas primeiras abordagens afirmam que fatores exógenos são os influenciadores exclusivos das ações dos Estados. O terceiro enfoque, contudo, ressalta a importância que os aspectos endógenos apresentam à cooperação e a maneira como toda a relação humana pode ser uma variável significante para o estabelecimento de interação entre os Estados. Krasner (2012) nomeia a vertente como abordagem grociana. Pressupõe-se que as ideias, as crenças, os valores e as normas são quesitos primordiais presentes na interação entre as nações. Sendo assim, observa-se, na abordagem, a participação construtivista como base teórica, em que se pode encontrar a presença de autores como Donald Puchala e Raymond Hopkins, Oran Young, Friedrich Kratochwil, entre outros. O campo analítico sugere duas teorias principais: o construtivismo fraco e o construtivismo forte.

O primeiro assume a importância da racionalidade dos atores e da busca pela maximização dos ganhos; entretanto, o que o agente compreende como racional não é uma condição dada, já que os atores dependem do conhecimento para perceber suas utilidades e moldar suas ações. Os teóricos subentendem três principais aspectos modeladores do conhecimento: a função interpretativa, uma vez que o conhecimento é gerado a partir da interpretação; o papel da comunidade epistêmica, que auxilia os tomadores de decisão ao disponibilizar informações científicas; e o mérito da intersubjetividade, a qual contém ideias pré-definidas dos problemas e das preocupações. Os construtivistas fortes asseveram que os atores agem conforme suas identidades; essas, por sua vez, podem ou não ser racionais. A preocupação gira em torno de como as identidades são formadas e como elas influenciam o conhecimento que, por seu turno, leva à criação dos regimes (HASENCLEVER, MAYER; RITTBERGER, 1997).

Consoante à importância das teorias de regimes internacionais, percebese que a OMC possui papel relevante na propagação do regime internacional do comércio. Uma Organização Internacional Governamental (OIG) de porte global atua no sistema internacional de duas formas, como mecanismo e como ator. Considerando a primeira característica, a OMC torna-se palco de discussão para os seus membros, dissemina informações, possibilita a consulta técnica, apresenta-se como um lócus onde os países têm voz, ou seja, disponibiliza uma série de instrumentos que promove e fortifica o regime de comércio. Como ator, a instituição é responsável por favorecer a legitimação das normas e regras do comércio internacional (WTO, 2017d).

Dessa maneira, ressalta-se a importância dos regimes internacionais para atenuar as diferenças econômicas entre os Estados. Young (1989) acentua como 
o "terceiro mundo" pode utilizar-se dos regimes para clamar por uma nova ordem econômica internacional. Seguindo esse pressuposto, o OSC, pautado na igualdade de participação dos países e na não discriminação, serviria como um meio de se alcançar menores desigualdades entre os países no aspecto comercial. O Órgão apresenta-se como um dos principais mecanismos da organização, já que a possibilidade de resolver disputas é fundamental para o sistema multilateral de comércio (WTO, 2017c).

\section{O Órgão de Solução de Controvérsias e a participação dos países em relação a seus níveis de desenvolvimento}

O OSC, desde a sua criação, revelou-se como um aparato institucional requisitado pelas nações que intencionavam utilizá-lo como um meio para conter as irregularidades do comércio internacional. Em comparação ao sistema solucionador de controvérsias do Gatt, o OSC apresentou, em média, um total de contenciosos 3,5 vezes maior (AZEVÊDO, 2015; WTO, 2017a) ${ }^{4}$. Ao longo dos seus 22 anos de atividade, 514 contenciosos foram demandados ao Órgão. Esse número elevado de disputas mostra a relevância de se compreender as características do processo decisório do OSC, desde o estabelecimento de uma contenda ao seu resultado final ${ }^{5}$. Sob esse prisma, encontra-se, a seguir, uma análise minuciosa do desenrolar dos processos, com enfoque nas participações entre as nações baseada nos distintos graus de desenvolvimento.

No que diz respeito ao número de demandantes, nota-se que, dos $514^{6}$ contenciosos, 299 tiveram os países desenvolvimento como interpelantes, 242 foram

4 O Gatt, durante sua vigência, foi responsável pelo tratamento de 300 contenciosos, o que configura a média de 6,38 disputas por ano. Por sua vez, a média anual do OSC é de 23,36 contendas.

5 Os contenciosos que ocorrem no OSC podem passar por quatro fases. A primeira, denominada Consulta, é menos formal. Nela, um país demonstra uma insatisfação nas relações comerciais com outro e demanda esclarecimentos. Caso o problema não seja resolvido, segue-se para a fase do Painel. Os painelistas são responsáveis por definir os prazos dos procedimentos das disputas e, ao final, fazem recomendações de conduta para as partes conflitantes. Quando um ator fica insatisfeito com o resultado do Painel, ele possui o direito à Apelação, que é a terceira fase. O Corpo de Apelação pode concordar, modificar ou divergir das considerações proferidas pelo Painel. A última etapa é a adesão às recomendações. Nesse momento, serão estabelecidos os prazos e as formas pelas quais os Estados entrarão em conformidade com as decisões do Painel ou da Apelação. Caso as decisões não sejam cumpridas, o país prejudicado pode solicitar medidas compensatórias, suspensão de concessões ou outras obrigações (WTO, 1994).

6 O somatório dos países demandantes $(299+242+1)$ é maior do que o número de contenciosos (514) devido à necessidade de efetuar a contagem de 35 demandantes nas contendas que possuem mais de um país como interpelante: DS217, com nove demandantes; DS35, com seis; DS27 e DS158, com cinco cada uma; DS16 e DS58, com quatro cada uma; e a DS234, com dois. Tem-se: $514+35=542$ demandantes. 
iniciados por países em desenvolvimento e apenas um país menos desenvolvido, Bangladesh, foi responsável pela abertura de uma disputa (WTO, 2017a). Em números absolutos, a discrepância entre as nações não é tão evidente quando se compara os PED em relação aos PD. Contudo, a assimetria torna-se mais notória se analisada a atuação dos Estados proporcionalmente, uma vez que os PED e os PMD representam mais de três quartos dos países-membros da OMC e demandaram, em contraste, apenas 44,8\% das disputas (WTO, 2017a). Outrossim, a desigualdade é ostensiva se observada a atividade dos PMD perante o órgão, em todas as fases e características dos processos de resolução de conflito.

Figura 1. Relação de abertura de contenciosos anualmente por classe de país (1995-2016)

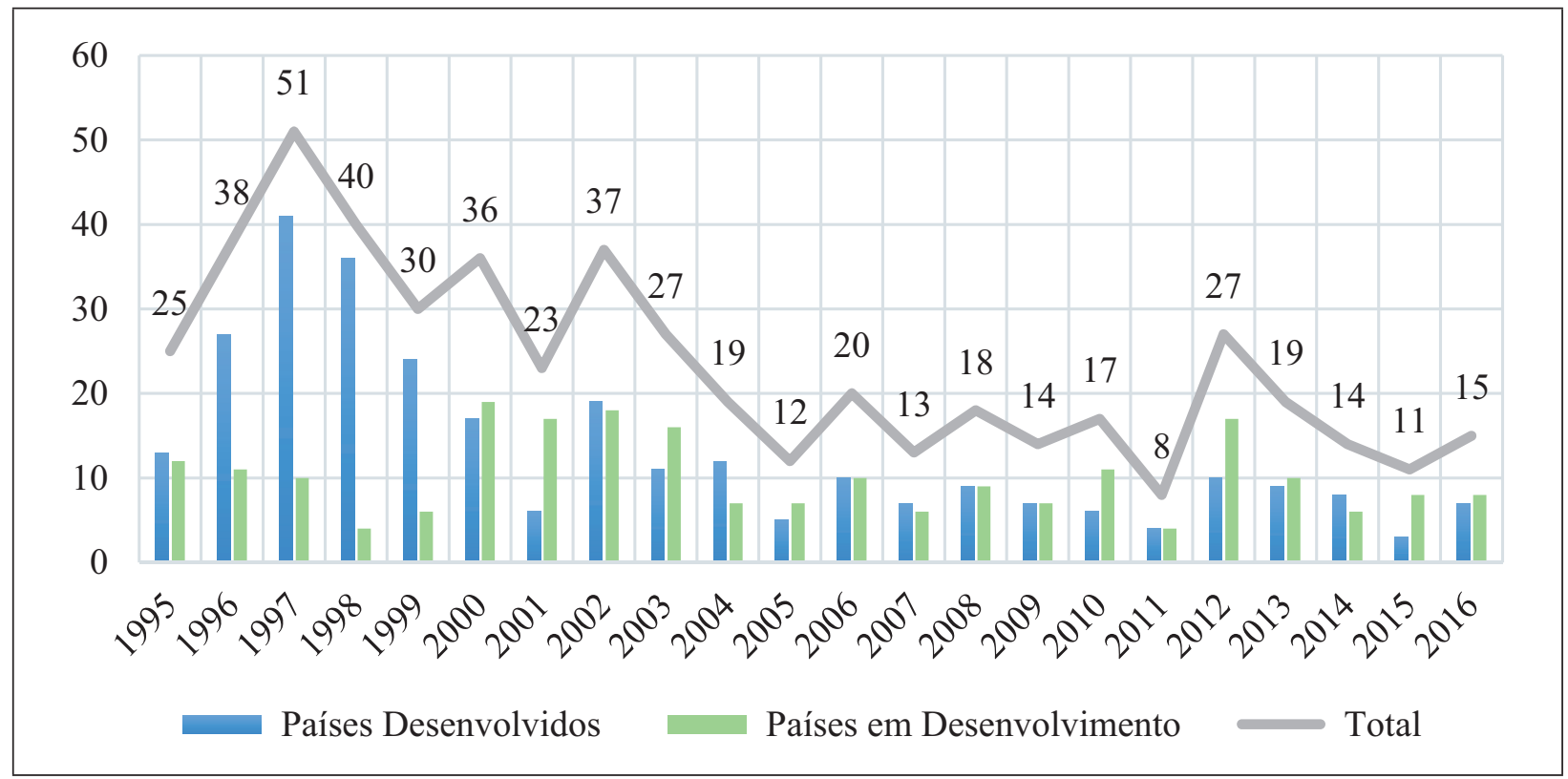

Fonte: WTO, 2017a.

Os dez primeiros anos de vigência do OSC contaram com um número maior de disputas, em relação aos últimos 12 anos. Os anos iniciais foram reveladores das ações dos Estados com maior poder econômico e com disponibilidades superiores de recursos como demandantes de novos contenciosos ao OSC. Entretanto, a partir de 2000, observa-se uma mudança no domínio de demandas por parte dos PD, posto que os PED somaram o montante de 30 contenciosos a mais em correspondência aos PD. A Figura 1 ilustra a quantidade de contenciosos abertos anualmente até 2016.

Os países com maiores números de contenciosos iniciados no órgão foram os Estados Unidos (EUA), com 111, a União Europeia (UE), com 97, e o Canadá, com 
35, os quais, juntos, representam o mesmo montante de contendas abertas por todos os PED e por Bangladesh - 243 disputas. Nesse sentido, torna-se, mais uma vez, evidente a discrepância de participação diante do OSC. Contudo, ressalvas devem ser feitas. A União Europeia, por exemplo, atua como Estado membro unitário, situação que contribui para o aumento da cifra. Ademais, presencia-se uma atuação relevante de alguns países em desenvolvimento, sobretudo das nações emergentes. O Brasil caracteriza-se como a parte mais atuante em interpelações dentre os PED, fator que o posiciona como o quarto país com o maior número de contendas abertas (30). De mesma maneira, Índia (23), México (23) e Argentina (20) demonstram participações consideráveis (WTO, 2017a).

Para Árabe Neto e Lopes (2012, p. 331), os BICS (Brasil, Índia, China e África do Sul, desconsiderando a Rússia) tornaram-se “atores relevantes em ambas as posições, ofensivas e defensivas" no que concerne às disputas internacionais de comércio. Por sua vez, Aguiar (2014, p. 172) postula que a participação dos BRICS (Brasil, Rússia, Índia, China e África do Sul) no OSC foi responsável pela "transição no paradigma da predominância da utilização do mecanismo pelos países desenvolvidos”. Alega-se que, excetuando-se os gargalos de participação da coalizão, os BRICS atuam como influenciadores nas atividades das outras nações em desenvolvimento/emergentes no órgão. A Figura 2 elucida o número de contendas por membros.

Figura 2. Quantidade de interpelações por membro (1995-2016)

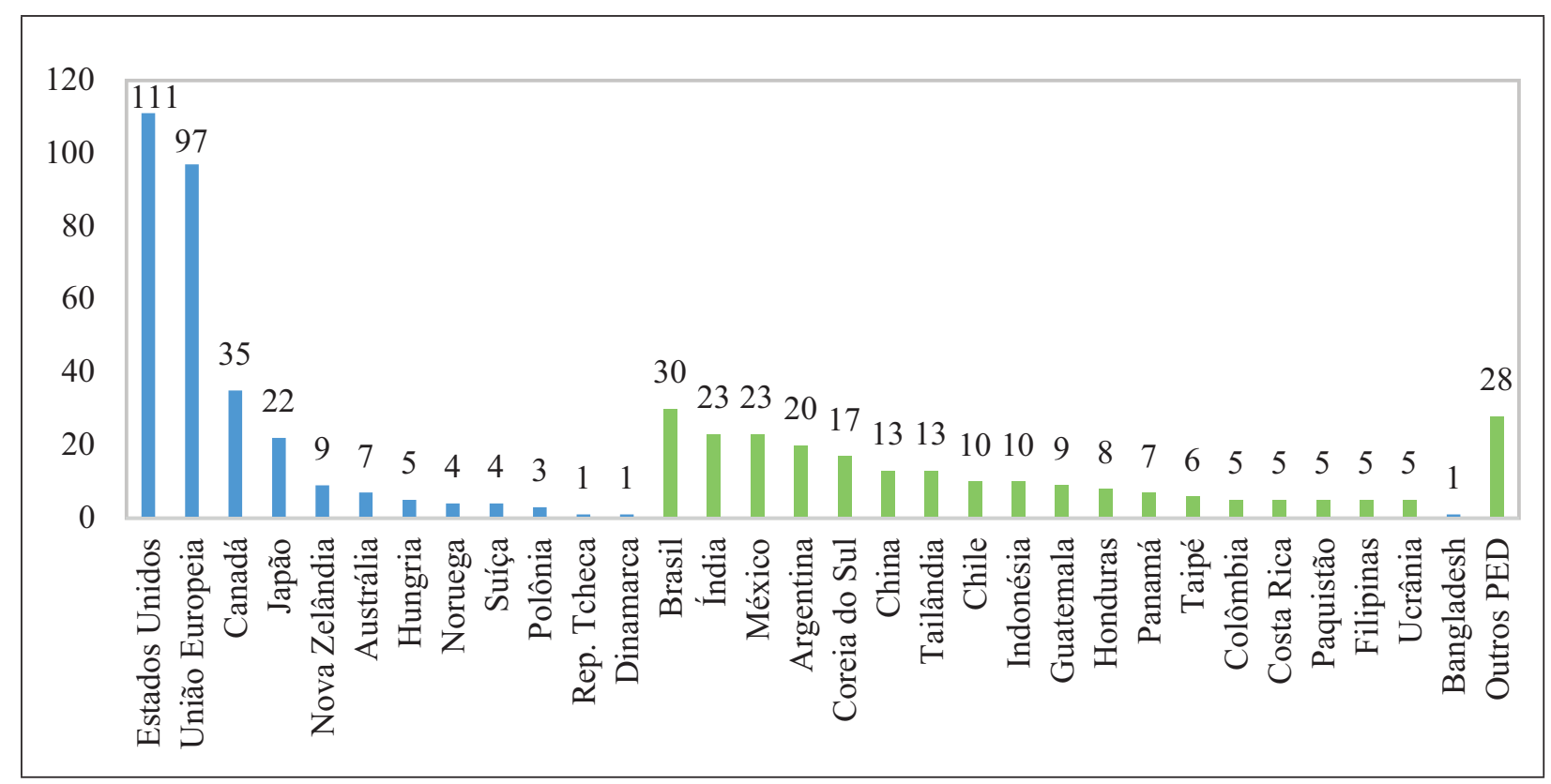

Fonte: WTO, 2017a. 
Apesar de alguns países em desenvolvimento mostrarem-se progressivamente como atores de importância no OSC - Brasil e Índia, por exemplo - , as nações de menores rendas ainda continuam à margem das atividades. O continente africano, no qual se encontra o maior número de PMD, demonstra uma participação ínfima no tocante à utilização do órgão solucionador de conflitos comerciais. Apenas três países da região atuaram diretamente em contenciosos, nenhum deles como demandante. Marrocos, Egito e África do Sul foram questionados, respectivamente, uma, quatro e cinco vezes. Todas essas contendas tiveram como demandantes outros PED, com exceção da DS305, na qual os EUA questionaram o Egito a respeito das tarifas aplicadas pelo último a certos produtos têxteis e de vestuário. Ressalta-se que, até 2016, nenhuma disputa teve como vitorioso um país africano (WTO, 2017a).

\section{Figura 3. Quantidade de disputas por membro interpelado (1995-2016)}



Fonte: WTO, 2017a.

No que se refere às partes interpeladas, os PED foram acionados em 44,5\% dos contenciosos. Em mesma análise feita por Lopes (2014), esses países tinham sido questionados em $33,81 \%$ dos casos. Nesse sentido, percebe-se que, em um período de dois anos, a cifra subiu mais de $10 \%$, valor que ilustra, possivelmente, uma caracterização desses países como sendo atores econômicos mais expressivos. Os $\mathrm{PD}$, por seu turno, seguem como os mais significativos nessa categoria, dado que os EUA (182) e a União Europeia (82) foram os membros que mais responderam às contendas. Ressalta-se a situação chinesa, visto que o país prestou satisfações 
37 vezes ao OSC, questionado, em maior parte, pelos EUA (19) e pela UE (8). O montante é ainda mais arrebatador ao notar que a adesão da China à OMC ocorreu apenas em 2001. A Figura 3 analisa a quantidade de membros com o status de interpelados.

Averígua-se que nenhum país menos desenvolvido foi interpelado no OSC. Esse aspecto é altamente positivo, no sentido de que os PMD não necessitam arcar com os altos custos financeiros e políticos oriundos do processo de responder a um contencioso, ademais, não tem suas ações comerciais questionadas. Todavia, o não envolvimento direto em uma disputa acarreta uma maior dificuldade de os PMD se mobilizarem em busca de um sistema multilateral de comércio mais justo.

A esse respeito, a participação desse grupo de países no OSC dá-se, excetuando-se o caso de Bangladesh7, exclusivamente como terceiras partes. Contudo, apenas cinco países, dos 44 listados com o status de menos desenvolvidos pela Organização das Nações Unidas (UN, 2015), atuaram como observadores em disputas. Malawi (6 disputas), Tanzânia (3 disputas), Senegal (2 disputas), Bangladesh (1 disputa) e Benin (1 disputa) foram os únicos PMD nessa categoria. O montante de participação representa somente $0,57 \%$ do somatório das atividades totais como terceiras partes. Ao todo, os membros da OMC atuaram como espectadores 2.294 vezes, das quais os PED tiveram um percentual considerável, marcando a grandeza de $66 \%$, com 1.516 participações. Por sua vez, os PD foram responsáveis por não mais que $33 \%$ da quantidade total, operando 765 vezes (WTO, 2017a).

Não obstante a maior participação dos PED, os PD continuam sendo os primeiros do ranking. Desse modo, Japão (163), União Europeia (159), Estados Unidos (134) e Canadá (114), juntos, exerceram atividades indiretas em 570 ocasiões. Ademais, destaca-se a atuação dos PED, principalmente dos países emergentes, que marcaram cifras próximas às dos PD. China (133), Índia (121), Brasil (105), Coreia do Sul (105) e Taipé (92) foram os mais ativos da categoria (WTO, 2017a).

No que concerne aos assuntos, assinala-se que ambos os grupos de países demandaram contenciosos referentes a bens, exclusivamente, com 255 contendas abertas pelos PD e 222 pelos PED, nesse setor. Apenas uma pequena quantidade de disputas foi, unicamente, relativa ao setor de serviços - cinco questionamentos por parte dos PD e, igualmente, cinco dos PED. Observa-se uma considerável discrepância em relação às disputas que tiveram como assunto somente a

7 A disputa iniciada por Bangladesh - único PMD interpelante - tinha como assunto bens, especificamente, produtos eletrônicos. Bangladesh questionou a Índia em relação à adoção de uma medida de antidumping sobre as importações de baterias de chumbo bangladeshianas (WTO, 2017a). 
propriedade intelectual: os PD iniciaram 19 interpelações contra apenas 3 dos PED. Alguns contenciosos tiveram mais de um tipo de assunto em uma única disputa. Nesse sentido, bens e propriedade intelectual foram solicitados ao OSC em cinco oportunidades pelos PD e em um mesmo número de vezes pelos PED; bens e serviços foram questionados em oito ocasiões por cada grupo de países; e serviços e propriedade intelectual foram levantados por países desenvolvidos em apenas dois contenciosos (WTO, 2017a).

Ao se observar, especificamente, os assuntos que fizeram parte das disputas do OSC, percebe-se que, em maior parte, foram efetuados questionamentos a respeito dos tratamentos comerciais de alimentos - não animais - e produtos agrícolas, tanto pelos PD (52 contendas) quanto pelos PED (48 contendas), sendo que laticínios e bananas apresentaram maior número de disputas nessa categoria. Por seguinte, acordos e tarifas: PD questionando 45 contendas e os PED, 27, com destaque às medidas impostas a importações e à prática tarifária estadunidense intitulada Zeroing. Animais e produtos derivados seguem no ranking dos assuntos mais questionados (PD, 40; e PED, 28), tendo maior incidência contendas relacionadas às aves, principalmente, à carne de frango. Os minerais e produtos derivados (PD, 30; PED, 44) configuram os outros tipos de assuntos mais demandados ao OSC, com ênfase ao aço (WTO, 2017a).

Por fim, os acordos da OMC foram questionados por meio dos contenciosos 1.167 vezes. Com relação aos acordos questionados pelas nações desenvolvidas, $76,3 \%$ dos casos envolveram o Gatt 1994, 24,4\% foram relativos a subsídios e medidas compensatórias, $18,7 \%$ à agricultura e 13,4\% a questões de antidumping. Por seu turno, o comportamento dos PED assemelhou-se ao dos PD, em que os acordos mais questionados foram o Gatt 1994, antidumping, subsídios e estabelecimento da OMC, representando $79,9 \%, 31,3 \%, 17,3 \%$ e 16,9\% de suas disputas, respectivamente. Acordos relacionados à agricultura e às medidas de salvaguarda também revelaram grandes demandas por parte dos PED, apontando 10,7\% ambos (WTO, 2017a).

\section{Evolução dos conflitos}

A inicialização de um contencioso é efetuada pela fase da consulta, o que pode evidenciar soluções sem a necessidade de estabelecimento de painéis. Dos 514 contenciosos, 69 foram solucionadas na fase da consulta, dentre eles, 47 dos PD 
como interpelantes e 22 dos PED. Nessa etapa, as contendas solucionadas foram classificadas em: acordo mútuo; disputa substituída por outra; disputa terminada; ou retirada da denúncia. Apurou-se que 153 contenciosos permanecem há mais de dois anos sem nenhum procedimento tomado nessa fase, ou seja, há uma inação por parte do OSC ou dos países envolvidos em prosseguir com essas disputas. O OSC conta com 14 contenciosos aguardando procedimentos com menos de dois anos na fase de consulta (WTO, 2017a).

291 casos seguiram para procedimentos mais formais, com o estabelecimento de painéis. Apresentam-se 87 disputas resolvidas nessa fase, 47 interpeladas pelos PD e 40, pelos PED, as quais revelam como resultados: acordo mútuo; decisão do painel; disputa terminada; ou painel suspenso. Dentre elas, 44 aguardam soluções. Além disso, 145 contendas tiveram as soluções dos painéis questionadas, encaminhando-se então para a apelação. A fase solucionou 119 contenciosos, dos quais 76 foram demandados pelos PD e 43, pelos PED. A apelação deixou quatro contendas em andamento e duas aguardando implementações. Por fim, 22 conflitos foram levados até a fase da arbitragem. Todos esses foram esclarecidos, tendo como categorias: acordo de implementação; acordo mútuo; decisão do corpo de apelação; ou retaliação permitida (WTO, 2017a).

Com o intuito de se compreender a efetividade do OSC, efetuou-se o cálculo da Taxa de Solução de Controvérsias, que consiste na porcentagem das disputas resolvidas em relação a todas as contendas existentes (excluindo-se aquelas em andamento ${ }^{8}$. A seguir, encontra-se a fórmula utilizada para o cálculo da taxa.

$$
\mathrm{TS}=\frac{\mathrm{Qc}+\mathrm{Qa}+\mathrm{Qr}}{\mathrm{Ct}-(\mathrm{Cec}+\mathrm{Cep}+\mathrm{Cea})} \times 100
$$

Na qual:

TS - Taxa de Solução do Órgão de Solução de Controvérsias;

Qc - Quantidade de contenciosos solucionados na fase da consulta;

Qp - Quantidade de contenciosos solucionados na fase do painel;

Qa - Quantidade de contenciosos solucionados na fase da apelação;

Qr - Quantidade de contenciosos solucionados na fase da arbitragem;

Ct - Contenciosos totais solicitados no Órgão de Solução de Controvérsias;

Cec - Contenciosos que devem ser excluídos na etapa da consulta, evidenciados por solicitações dos países entre 2015 e 2016;

8 A disputa referente a Bangladesh foi inserida nos cálculos referentes aos PED. 
Cep - Contenciosos que devem ser excluídos na etapa do painel, nesse caso, as questões ainda sendo resolvidas;

Cea - Contenciosos que devem ser excluídos na etapa da apelação, nesse caso, as questões ainda sendo resolvidas.

Apresenta-se como resultado de todos os 514 contenciosos:

$$
\mathrm{TS}=\frac{69+87+119}{514-(14+44+06)} \times 100=66,0 \%
$$

Efetuado o cálculo, evidencia-se que $66,0 \%$ dos contenciosos estabelecidos perante o OSC foram resolvidos. Mesmo revelando-se acima de 50\%, o valor é questionável, visto que a função principal do órgão é possibilitar a todas as contendas internacionais soluções satisfatórias. Considera-se que o processo de análise pode sofrer alterações profundas, evidenciadas pela existência das 153 disputas estagnadas na fase de consulta, contribuindo para a baixa do índice. Tais contenciosos, no entanto, podem ter sido solucionados por meio de acordos mútuos entre as partes, porém, sem prestação de contas ao OSC, o que o impossibilita de classificá-los como resolvidos. Para efeito de comparação, a taxa de solução em 2006 era de $49 \%$ (LUCENA, 2006), figurando ao OSC um salto de 17,0\% dos contenciosos solucionados, de maneira a atribuir maior otimismo ao desempenho do órgão.

A taxa de solução dos países em desenvolvimento é obtida pela aplicação da fórmula:

$$
\mathrm{TS}=\frac{22+40+43+06}{223-(12+24+05)} \times 100=60,98 \%
$$

Por sua vez, a taxa de solução dos países desenvolvidos é determinada por:

$$
\mathrm{TS}=\frac{47+47+76+16}{291-(02+20+01)} \times 100=69,40 \%
$$

Percebe-se que a taxa de solução de controvérsias dos PED em relação aos PD é $8,46 \%$ menor. Como já explicitado, uma das principais motivações que influenciam as ações dos países perante o OSC é a possibilidade de solucionar 
suas contendas. Uma taxa de solução menor para os países mais sensíveis economicamente demonstra a discrepância de atuação. O percentual revela que, além de apresentarem uma maior participação em praticamente todas as categorias dos processos, os PD conseguem resolver seus contenciosos de um modo mais eficaz em comparação aos PED.

Com relação aos resultados das disputas, os PD destacam-se como sendo as nações que mais obtiveram vitórias nos contenciosos. Esse grupo venceu 35,42\% (192 contendas), em relação ao número total de disputas (542) e, em contrapartida, os PED alcançaram êxito em 23,80\% (129 contendas). A cifra denuncia, nas palavras de Lopes (2014, p. 41), “que há uma desigualdade na acessibilidade ao sistema do OSC, que afeta principalmente os países [em desenvolvimento e] menos desenvolvidos”.

Figura 4. Duração dos contenciosos solucionados

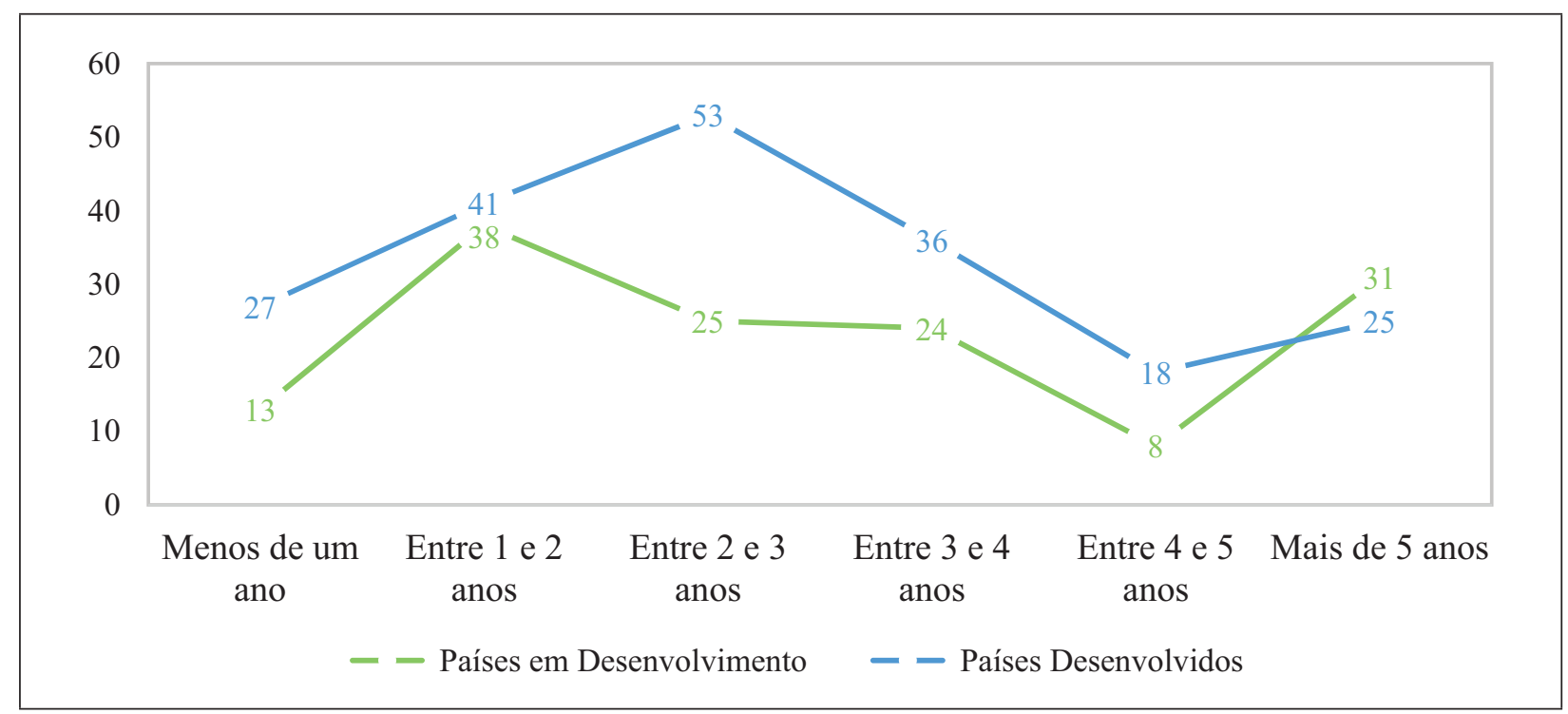

Fonte: WTO, 2017a.

Por último, analisa-se o tempo de resolução dos conflitos. A Figura 4 ilustra que, em sua maioria, as disputas de ambos os grupos de países levaram menos de três anos para alcançar soluções. Os números mostram-se positivos, pois desvelam que as contendas solucionadas tramitaram com prazos próximos aos estipulados no Entendimento sobre Regras e Procedimentos de Soluções de Controvérsias (ESC). Contudo, é preciso dar atenção aos 56 contenciosos que demandaram mais de cinco anos para serem concluídos, o que diminui a credibilidade do órgão, sobretudo porque esse montante evidencia uma certa incapacidade de que as normas referentes aos prazos sejam respeitadas. 


\section{Assimetrias de participação no OSC e as teorias dos regimes}

Os regimes estão conectados à ideia de ordem internacional (YOUNG, 1989). Nessa perspectiva, na área comercial, compreende-se como ordem econômica internacional o pressuposto de que os países podem, livremente, comprar e vender em uma rede de mercados internacionais. Não obstante, deve-se questionar a existência da liberdade comercial no sistema internacional, uma vez que os países menos desenvolvidos e em desenvolvimento acabam convertendo-se em reféns do papel a eles atribuídos na divisão internacional do trabalho. O OSC, dessa maneira, reflete essa divisão, fator identificado quando se analisa as assimetrias das participações em todas as categorias dos contenciosos. De fato, as assimetrias de participação dos PMD, PED e PD nas diversas categorias de um contencioso foram fortemente identificadas. O Quadro 1 resume o nível de desigualdade presente na atuação desses grupos de países.

Quadro 1. Resumo das assimetrias de participação por grupo de países (1995-2016)

\begin{tabular}{|lccc|}
\hline \multicolumn{1}{|c}{ CATEGORIAS } & PD & PED & PMD \\
\hline Países membros & $7,98 \%$ & $65,03 \%$ & $26,99 \%$ \\
Demandantes & $55,17 \%$ & $44,65 \%$ & $0,18 \%$ \\
Demandados & $55,44 \%$ & $44,55 \%$ & - \\
Terceiras partes & $33,35 \%$ & $66,09 \%$ & $0,57 \%$ \\
Tempo médio & Entre 2 e 3 anos & Entre 1 e 2 anos & - \\
Vitórias & $35,42 \%$ & $23,80 \%$ & - \\
Taxa de solução & $69,40 \%$ & $60,98 \%$ & - \\
\hline
\end{tabular}

Fonte: elaborado pelos autores com dados da WTO, 2017a.

As assimetrias, na maioria dos casos, são consideradas negativas para os países em desenvolvimento e para os menos desenvolvidos. Observa-se que, mesmo sendo membros numerosamente significantes da instituição, esses grupos não conseguem ter uma atuação em consonância com as suas demandas. As discrepâncias descrevem os empecilhos que os Estados com menores rendas enfrentam em um comércio internacional injusto. As teorias dos regimes internacionais, nesse contexto, podem oferecer argumentos plausíveis capazes de explicar essas assimetrias.

Contudo, um estudo pautado por apenas uma proposta teórica pode espelhar uma investigação deficitária. Strange (1994) aponta que os estudantes da economia 
política internacional são, frequentemente, pressionados a escolher um cardápio dentre os três possíveis: o realismo, o marxismo ou o liberalismo. No entanto, a autora afirma ser impossível haver uma única teoria capaz de abranger todas as características e níveis de análise de uma determinada situação. Desse modo, as metodologias de análise devem ser capazes de, dentre esses cardápios, "escolher um aperitivo do realismo, um prato principal do liberalismo e uma sobremesa do marxismo"9 (STRANGE, 1994, p. 16, tradução dos autores), ou seja, eleger mais de um arcabouço explicativo para um estudo.

A abordagem baseada no poder mostra-se relevante para explicar a atuação dos Estados quando estes recorrem ao OSC visando a uma manutenção e/ou expansão de poder. O poder deve ser compreendido como as capacidades possuídas por um país. No caso específico da esfera comercial, pode-se considerar poderoso aquele grupo de Estados que detêm um elevado Produto Interno Bruto (PIB) e uma alta participação nas exportações mundiais. Os PED e os PMD apresentam um montante de PIB um pouco maior do que os PD - enquanto os PED têm $52 \%$ e os PMD, $1 \%$, os PD possuem $47 \%$. Com relação à participação nas exportações, os PED e os PMD são responsáveis por $78 \%$ dos valores das exportações de todos os países membros da OMC. Uma conclusão precipitada a partir desses números poderia demonstrar que os PED e os PMD têm mais poder.

Entretanto, é preciso incluir na análise acima o número de países que participam de cada grupo: 69 nações são PED, 8 são PMD e 24 são PD. Ao se fazer uma média do PIB e do valor exportado por grupo de países, a compreensão do poder se modifica. O PIB médio dos PD é mais do que o dobro que o dos PED, no entanto, mesmo ao se considerar a média, a participação nas exportações dos PED e dos PMD ainda é superior aos PD. Os Países Desenvolvidos, apesar de terem maior PIB médio, possuem menor participação no total das exportações (UNCTAD, 2018). Assim, os elevados recursos que os PD possuem e que podem bancar os custos dos processos no OSC e a menor participação desse grupo de países no total das exportações podem explicar o fato de esses países terem uma participação maior no OSC.

Como as exportações fazem parte do PIB, os PD, portanto, se engajam fortemente no OSC porque querem manter seu PIB elevado e não podem perder mercado para os seus produtos. O tamanho pequeno do PIB, em resumo, é uma barreira à entrada no OSC. Para confirmar essa hipótese, pode-se mencionar o

$9[\mathrm{~T}] \mathrm{o}$ pick an appetizer from the realists, a main course from the liberals and a dessert from the Marxists. 
estudo realizado por Lucena e Mendonça (2017), que utilizou o modelo gravitacional para verificar se as exportações estadunidenses, no início de cada disputa, são influenciadas pelo PIB dos países que estão participando do contencioso. Os resultados mostraram que as exportações norte-americanas são influenciadas pelo PIB do país da disputa.

As teorias de interesse, por seu turno, promovem uma análise também pertinente, sobretudo quando se questiona o porquê de os Estados continuarem cooperando, por meio do OSC, mesmo havendo assimetrias muito evidentes. A existência de uma sombra sobre o futuro, um conceito utilizado pelas teorias baseadas no interesse, pode explicar a cooperação, no curto prazo, mesmo em condições adversas. A sombra do futuro significa que os Estados, por terem dúvidas sobre o futuro, adotam estratégias de longo prazo com os objetivos de obterem mais informações e de desenvolverem condições mais adequadas para si. Os Estados, nesse caso, mesmo não tendo condições momentâneas de defenderem seus interesses, presumem que a cooperação é a melhor estratégia porque, no longo prazo, eles poderão ter melhores condições e alterar o resultado do jogo. Nesse sentido, quando se observa, no Quadro 1, que os países que participam dos contenciosos como terceiras partes, verifica-se que aproximadamente $67 \%$ deles fazem parte do grupo dos PED e PMD. Participar como terceira parte é uma estratégia dos PED e PMD que visa conhecer os trâmites de uma disputa até obter informações suficientes para defender seus interesses no longo prazo. O horizonte de tempo das contendas abertas perante o OSC também confirma essa hipótese, pois os conflitos que envolvem os países desenvolvidos são resolvidos mais rapidamente. As disputas dos PD, de acordo com o Quadro 1, levam entre um e dois anos para serem solucionadas, e as dos PED, entre dois e três anos.

Os países desenvolvidos, entretanto, adotam uma estratégia de longo prazo quando percebem que têm uma elevada probabilidade de perda no curto prazo. A lógica por trás dessa estratégia é ganhar tempo para fortalecer o setor econômico doméstico e, assim, criar as condições para competir com os demais países. Como exemplo, observa-se a atuação dos EUA. Quatro contendas merecem destaque: DS160, solucionada em 2003; DS176, resolvida em 2002; DS184, terminada em 2001; e DS217, em 2004. Todos esses contenciosos evidenciaram derrota estadunidense. O marcante é que, mesmo passada mais de uma década, o Estado ainda não entrou em conformidade, tal como sugerido pelo OSC. Além disso, os EUA, até dezembro de 2016, enviaram relatórios mensais com a alegação de que estão trabalhando para que as medidas entrem em consonância com as recomendações 
da instituição. Aqui, é possível acrescentar outras duas prováveis explicações das teorias baseadas no interesse para a menor participação dos PED e PMD no OSC, que é a presença de questões de ligação e a experiência normativo-institucional.

A existência de questões de ligação entre os países, que são interesses que eles possuem em outras atividades desenvolvidas entre eles, pode desestimulá-los a entrarem em uma disputa porque aquele possível conflito comercial é apenas um dos interesses que aquele país tem com o outro e, caso ele não adote uma estratégia cooperativa, os demais interesses poderão ser afetados. Os membros, portanto, fazem uma análise do custo de oportunidade de entrar em uma disputa comercial: quanto ele terá que sacrificar nas relações comerciais com o país da disputa caso ele dê entrada em um processo no OSC contra aquele país. No início do contencioso DS250 entre Brasil e Estados Unidos, em 2002, as exportações de suco de laranja do Brasil eram de U\$ 137.914.385,00. No início do contencioso DS382 entre Brasil e Estados Unidos, em 2008, que também tratava do suco de laranja, as exportações do produto tinham subido 308\% no período 2002-2008 (MDIC - MINISTÉRIO DA INDÚSTRIA, COMÉRCIO EXTERIOR E SERVIÇOS, 2018). Entretanto, o Brasil, em 2002, exportava 2936 produtos para o mercado norte-americano e os fabricantes desses produtos temiam que os Estados Unidos comprassem menos deles por causa dos conflitos comerciais relacionados ao suco de laranja. Esse receio dos empresários brasileiros, especialmente se ele for expresso nas associações empresariais e nos fóruns onde empresa e governo debatem, pode influenciar o governo e fazer o mesmo ser mais cauteloso na abertura de novos contenciosos.

A experiência normativo-institucional também pode explicar as assimetrias existentes no OSC, pois, quanto mais experiente o país, maior a possibilidade de ele acionar as instituições internacionais para defender seus interesses. A qualidade da burocracia do governo, um indicador que pode ser utilizado como proxy para experiência normativo-institucional, é maior nos PD. Enquanto que, nesse grupo de países, ela é de 0,8 - em uma escala que varia entre zero e 1 , sendo que quanto mais próximo de 1 , melhor - , nos PED e PMD, ela é de 0,47 (DAHLBERG et al., 2018).

Por fim, as teorias baseadas no conhecimento fornecem uma ferramenta importante para se compreender as escolhas de um Estado-membro em iniciar uma disputa. O conhecimento é uma fonte muito relevante (HAAS, 1992), uma vez que os atores dependem dele para formularem estratégias plausíveis para a 
resolução de um determinado problema. De igual modo, o conhecimento influencia a própria percepção do que seria esse problema a ser combatido. Nesse aspecto, um conhecimento profundo acerca de uma contenda internacional pauta-se como variável impactante quando das interações dos membros perante o OSC. O papel da comunidade epistêmica afigura-se como um fator que influencia a adesão de conhecimento por parte dos atores.

Para iniciar e administrar uma disputa comercial, dois tipos de conhecimento são fundamentais para que um membro participe com êxito em um processo: o jurídico e o técnico. No concernente ao primeiro, ainda que as nações mais fracas economicamente não possuam um arcabouço jurídico satisfatório que as possibilite atuar mais ativamente perante o OSC, a própria OMC disponibiliza profissionais competentes para auxiliarem esses países nos trâmites processuais. O conhecimento técnico, aquele referente à natureza de uma disputa específica (como medidas fitossanitárias, propriedade intelectual etc.), é acionado consoante a capacidade de um ator/Estado em lidar com determinadas situações.

Nesse sentido, a relação entre os governos e a comunidade epistêmica, como sugere a terceira abordagem, apresenta-se como um quesito positivo quando se observa a participação perante o OSC e a existência de instituições científicas de qualidade em um determinado país. No banco de dados disponibilizado pelo QoG Institute, observa-se que as instituições científicas dos PD são de maior qualidade do que as do PED e PMD. Em uma escala de 1 a 7 , a qualidade das instituições científicas dos Estados desenvolvidos atingiram o índice de 5,14, enquanto aquelas dos menos desenvolvidos e em desenvolvimentos alcançaram 3,20 e 3,70, respectivamente (DAHLBERG et al., 2018). Outro indicador que pode servir como proxy para mensurar a robustez da comunidade epistêmica de um país é a quantidade de artigos publicados em periódicos científicos de acesso aberto. Em 2014, foram publicados no mundo 1.490 .237 artigos e os países desenvolvidos publicaram 1.130.422, o que significou $78 \%$ das publicações (SCIENCE-METRIX, 2018). Os dados respaldam a noção de que os membros mais desenvolvidos possuem maiores chances de acionarem suas instituições ricas em conhecimento, 0 que afeta suas formas de atuação perante o OSC, influenciando em um tratamento mais eficaz dos contenciosos.

Em suma, as teorias de regime podem auxiliar na compreensão de como os Estados atuam no OSC, já que explicam o comportamento de determinados atores e auxiliam de modo oportuno na interpretação de um conjunto de dados. 
Keohane e Nye (1987) postulam que os Estados estão gradativamente mais interdependentes, o que contribui para o aumento da cooperação entre eles. Contudo, ressalta-se que um aumento da interdependência não significa uma diminuição das assimetrias. Nesse sentido, compreende-se a relevância das instituições no que concerne à cooperação, pois elas não se limitam apenas a um mecanismo de interação entre os Estados, mas configuram um meio coordenador das relações dos atores. Com isso, as instituições funcionam como elementos capazes de reduzir as diferenças e as assimetrias de informações (KEOHANE, 1984).

\section{Considerações finais}

As teorias de regimes internacionais são importantes elementos que explicam as motivações cooperativas dos Estados e demais atores do sistema internacional. A incapacidade de produzir observações categoricamente holísticas, assim, não danifica a relevância das teorias como aparato esclarecedor, tampouco desvincula a importância dos regimes internacionais para a interação entre os atores e como esses influenciam a existência, criação e manutenção dos princípios, normas, regras e procedimentos. Nesse sentido, observou-se que as teorias de regimes baseadas no poder elucidam como os Estados membros atuam perante o OSC, tendo em vista adquirir maiores ganhos com a abertura de contenciosos. Nota-se que aqueles com maiores capacidades (PIB, montante de exportação) logram acessar o órgão mais facilmente, possuindo, desse modo, mais oportunidade de colocarem suas demandas em evidência.

As teorias que enfatizam o interesse, por sua vez, revelam que questões como a sombra sobre o futuro, a existência de questões de ligação entre os países e a experiência normativo-institucional influenciam na decisão de um Estado iniciar e/ou dar continuidade a um contencioso. Observou-se que os países que possuem instituições internas mais estáveis e organizadas, evidenciadas pelo índice de qualidade democrática, acionam o OSC com mais frequência. Outrossim, a ligação entre os países, destacada por suas relações comerciais, apresenta-se como outra característica importante na hora do cálculo de ação dos membros diante do OSC.

Por último, as teorias pautadas no conhecimento também auxiliam notoriamente na compreensão das assimetrias. O conhecimento de como se desencadeiam os 
processos na instituição apresenta-se como peça fundamental para se obter êxito nas questões tratadas. Posto isso, percebeu-se que a comunidade epistêmica é de grande valia. Os membros que possuem instituições de pesquisas mais bem qualificadas, somadas às suas fortes participações nos periódicos de pesquisa mundiais (artigos publicados), são proxies que destacam as possibilidades de acessar um conhecimento técnico e especializado, o que contribui para uma melhor participação no OSC.

A significância que o OSC possui como atenuador das assimetrias é clara, pois seu arcabouço de regras e de procedimentos incorpora diversas proposições com vistas a um tratamento diferenciado dos PED e dos PMD. Por esse ângulo, a instituição assume a existência de diferenças entre seus membros, as quais devem ser suprimidas por meio de um mecanismo normatizador capaz de diminuir as assimetrias e de atribuir maior igualdade de atuação. No entanto, os PED e os PMD encontram esses gargalos (PIB, qualidade das instituições, comunidade epistêmica) que os impossibilitam de acessar o órgão e, dessa forma, obter um tratamento diferenciado que contribuiria para um melhor posicionamento perante a instituição.

Nesse sentido, para que haja um tratamento eficaz, faz-se necessário haver uma atenção aos obstáculos que impossibilitam a esses países um acesso igualitário ao OSC. Caso contrário, o princípio de igualdade, fundamental para a OMC, não poderá ser um princípio primordial para a existência da instituição, pois um sistema em que a maioria dos membros não tem acesso ao seu órgão solucionador de controvérsias não pode ser considerado efetivo (LOPES, 2014).

Ainda que os PMD e os PED encontrem obstáculos em efetivar uma participação mais expressiva perante o OSC, deve-se atentar aos esforços e ao empenho desses Estados em lutar por uma instituição mais justa e eficaz, com o intuito de diminuir as desigualdades e de fomentar caminhos para o desenvolvimento. Essa articulação entre essas nações deu-se, sobretudo, a partir das últimas rodadas do Gatt, em que os países mais fracos começaram a expor seus anseios por meio de coalizões concretas e bem arquitetadas. Ainda que ineficaz em assegurar a igualdade, a OMC é primordial para que esses atores possuam uma ferramenta que os permita reivindicar um sistema comercial mais justo. Tampouco é oportuno menosprezar a tenacidade de atuação dos membros em formular um arcabouço institucional que preze pela igualdade. As assimetrias existem, cabe aos atores e à instituição promover meios capazes de minimizá-las. 


\section{Referências}

AGUIAR, L. A. Tratamento diferenciado dos países em desenvolvimento no Órgão de Solução de Controvérsias da Organização Mundial do Comércio. 2014. 177 f. Monografia (Graduação em Direito) - Faculdade de Direito, Universidade de São Paulo, Ribeirão Preto, 2014.

ALVES. A. R. C. O conceito de hegemonia: de Gramsci a Laclau e Mouffe. Lua Nova, São Paulo, n. 80, p. 71-96, 2010.

ÁRABE NETO, A. M.; LOPES, J. S. Atuação dos BICS no Órgão de Solução de Controvérsia da OMC. In: Thorstensen, V.; Oliveira, I. T. M. (orgs.). Os BRICS na OMC: Políticas Comerciais Comparadas de Brasil, Rússia, Índia, China e África do Sul. Brasília: Ipea, 2012. p. 331-397.

AZEVÊDO, R. A OMC aos 20 anos. Meridiano 47, Brasília, n. 150, p. 10-13, jul/ago, 2015.

DAHLBERG, S.; HOLMBERG, S.; ROTHSTEIN, B.; PACHON, N. A.; SVENSSON, R. The Quality of Government Standard Dataset, 2018. Gothenburg: The Quality of Government Institute, 2018. Disponível em: < http://www.qog.pol.gu.se doi:10.18157/ QoGBasJan18 > . Acesso em: 20 jul. 2018.

HASENCLEVER, A.; MAYER, P.; RITTBERGER, V. Theories of international regimes. Cambridge: Cambridge University Press, 1997.

HAAS, P. M. Epistemic communities and international policy coordination. International Organization, Cambridge, v. 46, n. 1, p. 1-35, 1992.

KEOHANE, R. O. After Hegemony: Cooperation and Discord in the World Political Economy. New Jersey: Princeton University Press, 1984.

KEOHANE, R. O; NYE, J. S. Power and Interdependence revisited. International Organization, Cambridge, v. 41, n. 4, p. 725-753, 1987.

KRASNER, S. D. Causas estruturais e consequências dos Regimes Internacionais: Regimes como variáveis intervenientes. Tradução de Dalton Guimarães, Feliciano Guimarães e Gustavo Biscaia de Lacerda. Revista de Sociologia e Política, Curitiba, v. 20, n. 42, p. 93-110, jun. 2012.

LOPES, I. Órgão de Solução de Controvérsias da OMC: acesso aos países em desenvolvimento? Revista de Direito da Universidade de Brasília, Brasília, v. 1, n. 1, p. 33-66, jul./dez. 2014.

LUCENA, A. F. Cooperar ou não cooperar, eis a questão: a Organização Mundial do Comércio, o Brasil e o contencioso Embraer-Bombardier. 2006. 292 f. Tese (Doutorado em Relações Internacionais) - Instituto de Relações Internacionais, Universidade de Brasília, Brasília, 2006.

LUCENA, A. F. Teorias de Regimes Internacionais. In: (org.). Regimes Internacionais: temas contemporâneos. Curitiba: Juruá, 2012. p. 33-57. 
LUCENA, A. F.; MENDONÇA, C. M. Disputas comerciais entre Brasil e Estados Unidos no Órgão de Solução de Controvérsias da Organização Mundial do Comércio. In: CONGRESSO DE ENSINO, PESQUISA E EXTENSÃO, 14., Goiânia. Anais eletrônicos... Goiânia: UFG, 2017. Disponível em: < http://eventos.ufg.br/SIEC/portalproec/sites/ site12721/site/arquivos/PIVIC.pdf. > . Acesso em: 06 ago. 2018.

MINISTÉRIO DA INDÚSTRIA, COMÉRCIO EXTERIOR E SERVIÇOS. Comércio Exterior. ComexStat-Exportação e Importação Geral. Disponível em: < comexstat.mdic.gov. br/pt/geral >. Acesso em: 20 jul. 2018.

MORGENTHAU, Hans J. A política entre as nações: a luta pela guerra e pela paz. Brasília: Editora Universidade de Brasília/ Instituto de Pesquisa de Relações Internacionais; São Paulo: Imprensa Oficial do Estado de São Paulo, 2003.

RUGGIE, John G. International responses to technology: concepts and trends. International Organization, Cambridge, v. 29, n. 3, p. 557-584, 1975.

SCIENCE-METRIX. Analytical support for bibliometrics indicators. Open access availabity of Scientifc Publications. Montreal: Science-Metrix Inc., 2018.

STRANGE, S. States and Markets. New York: Pinter Publisher, 1994.

UNITED NATIONS (UN). World Economic Situation and Prospects. New York: UN, 2015.

UNITED TRADE CONFERENCE ON TRADE AND DEVELOPMENT (UNCTAD). Data center. Disponível em: < http://unctadstat.unctad.org/wds/ReportFolders/reportFolders. aspx?sCS_ChosenLang $=$ en $>$. Acesso em: 22 jul. 2018.

WORLD TRADE ORGANIZATION (WTO). Understanding on Rules and Procedures Governing the Settlement of Disputes, 1994. Disponível em: < www.wto.org/english/ docs_e/legal_e/28-dsu.pdf > . Acesso em: abr. 2018.

. Disputes by country/territory. 2017a. Disponível em: < https://www.wto.org/ english/tratop_e/dispu_e/dispu_by_country_e.htm > . Acesso em: jun. 2017.

. General Agreement on Tariffs and Trade 1994. 2017b. Disponível em: < https://www.wto.org/english/res_e/booksp_e/analytic_index_e/gatt1994_01_e. htm\#article1C3aiv > . Acesso em: jul. 2017.

. Understanding the WTO. 2017c. Disponível em: < https://www.wto.org/english/ thewto_e/whatis_e/tif_e/understanding_e.pdf > . Acesso em: jul. 2017.

World Trade Report. 2017d. Disponível em: < https://www.wto.org/english/ res_e/booksp_e/world_trade_report15_e.pdf > . Acesso em: maio 2017.

YOUNG, O. R. International Cooperation: building regimes for natural resources and the environment. New York: Cornell University, 1989. 